\title{
PENERAPAN PRINCIPAL COMPONENT ANALYSIS UNTUK PENINGKATAN KINERJA ALGORITMA DECISION TREE PADA IRIS DATASET
}

\author{
Putri Kurnia Handayani ${ }^{1}$ \\ ${ }^{1}$ Fakultas Teknik Universitas Muria Kudus \\ Email: ${ }^{1}$ putri.kurnia@umk.ac.id
}

(Naskah masuk: 24 Juni 2020, diterima untuk diterbitkan: 29 Juni 2020)

\begin{abstract}
Abstrak
Data mining merupakan salah bidang ilmu yang bermanfaat untuk pengenalan pola/knowledge yang tersimpan dalam database. Klasifikasi merupakan salah satu peran dalam bidang data mining. Termasuk ke dalam supervised learning, klasifikasi digunakan untuk memprediksi objek yang belum memiliki kelas/label. Penggunaan algoritma decision tree untuk proses mining dataset bunga iris dikarenakan kemudahan dalam representasi knowledge yang dihasilkan. Selain itu, decision tree juga termasuk ke dalam eager learner sehingga akurasi dari knowledge yang dihasilkan lebih baik. Penggunaan principal component analysis (PCA) dalam optimasi algoritma decision tree, dilakukan saat preprocessing dataset. PCA berfungsi untuk mereduksi dimensi, fitur yang saling berkorelasi akan dipertahankan. Penggunaan dataset publik bunga iris diambil dari UCI Repository. Berdasarkan hasil perhitungan, akurasi algoritma decision tree setelah dilakukan optimasi dengan PCA terhadap dataset bunga iris sebesar $95.33 \%$.
\end{abstract}

Kata kunci: data mining, klasifikasi, decision tree, PCA

\section{IMPLEMENTATION OF PRINCIPAL COMPONENT ANALYSIS FOR IMPROVING DECISION TREE ALGORITHM PERFORMANCE IN IRIS DATASET}

\begin{abstract}
Data mining is a useful field of knowledge for pattern recognition / knowledge stored in databases. Classification is one of the roles in the field of data mining. Included in supervised learning, classification is used to predict objects that do not have a class / label. The use of decision tree algorithms for the iris dataset mining process is due to the ease in representing the knowledge generated. In addition, the decision tree is also included in the eager learner so that the accuracy of the knowledge generated is better. The use of principal component analysis (PCA) in the decision tree algorithm optimization is done during the preprocessing dataset. PCA functions to reduce the dimensions, correlated features will be maintained. The use of the iris public dataset is taken from the UCI Repository. Based on the calculation results, the accuracy of the decision tree algorithm after optimization with the PCA of the iris dataset is $95.33 \%$
\end{abstract}

Keywords: data mining, classification, decision tree, PCA

\section{PENDAHULUAN}

Data mining didefinisikan sebagai pencarian pola secara otomatis dalam database yang besar, menggunakan teknik komputasi dari statistik, machine learning dan pattern recognition (Gorunescu, 2011). Data mining adalah tentang bagaimana menyelesaikan masalah dengan cara menganalisis data yang tersedia dalam database ( (Witten, et al., 2011)

Klasifikasi merupakan salah satu dari lima peran utama data mining. Termasuk ke dalam kategori supervised learning, klasifikasi merupakan proses prediksi terhadap objek yang belum mempunyai kelas/label. Decision tree (DT) adalah classifier yang dinyatakan sebagai partisi rekursif dari dataset ( (Maimon \& Rokarch, 2010). Decision tree terdiri dari akar, cabang dan daun. Decision tree populer digunakan untuk proses klasifikasi karena kemudahan dalam representasi pola dataset (gambar 1). Selain digambarkan dalam bentuk pohon, hasil dari klasifikasi juga bisa direpresentasikan dalam bentuk aturan (rules). Pola yang terbentuk dari proses klasifikasi dapat digunakan sebagai saran bagi 
56 Indonesian Journal of Technology, Informatics and Science (IJTIS), Vol. 1, No. 2, Juni 2020, hlm. 55-58

manajemen dalam menentukan aturan atau kebijakan baru.

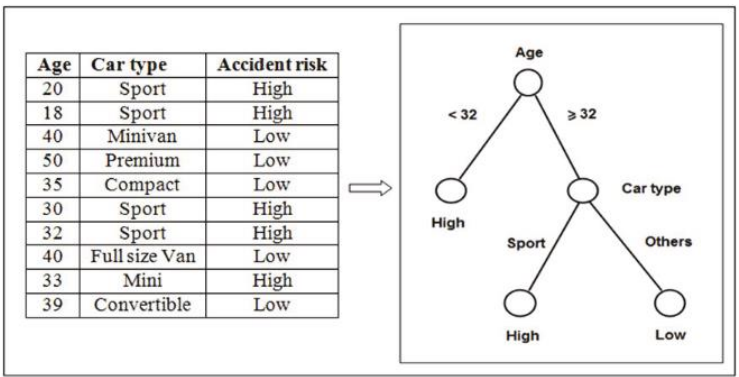

Gambar 1 Skema Decision Tree

\section{METODE PENELITIAN}

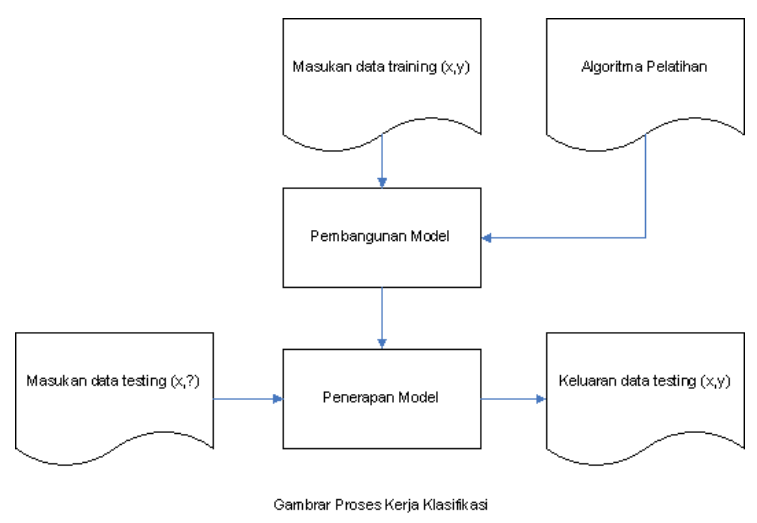

Gambar 2 Alur kerja klasifikasi

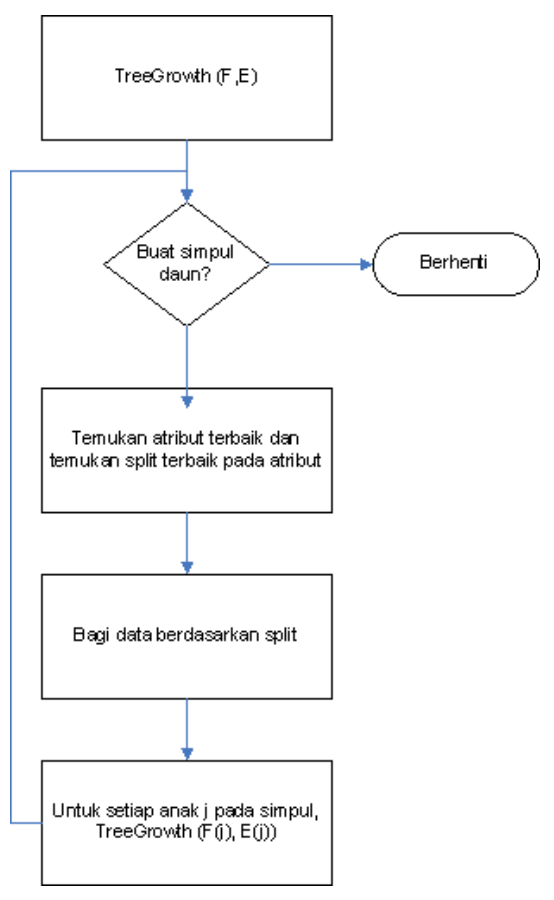

Gambar 3 Algoritma Induksi Decision Tree

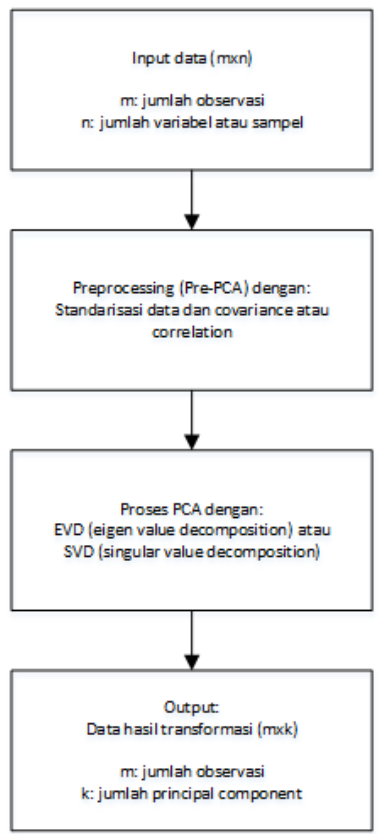

Gambar 4 Algoritma PCA

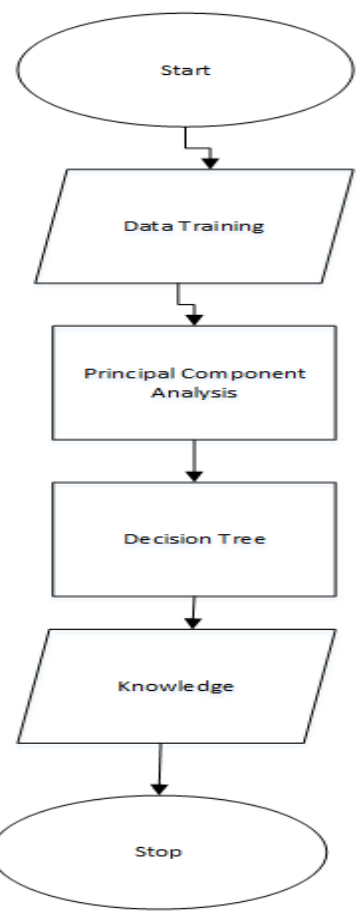

Gambar 5 Optimasi Decision Tree dengan PCA

\section{HASIL DAN PEMBAHASAN}

\subsection{Pengumpulan Data}

Iris dataset merupakan data public yang diambil dari UCI Repository. Data bunga iris terdiri dari 5 atribut, yaitu sepal length (a1), sepal width (a2), petal length (a3), petal width (a4) dan label yang berfungsi sebagai kelas/label. Dataset training terdiri dari 150 objek/record yang sudah berada pada kelas/label masing-masing, meliputi kelas iris setosa, iris versicolor dan iris virginica. Sampel dataset bunga iris dapat dilihat pada tabel 1 . 
Tabel 1 Data sampel bunga Iris

\begin{tabular}{lllll}
\multicolumn{5}{c}{ Tabel 1 } \\
Label & $\mathbf{a 1}$ & $\mathbf{a 2}$ & $\mathbf{a 3}$ & $\mathbf{a 4}$ \\
\hline Iris-setosa & 5.100 & 3.500 & 1.400 & 0.200 \\
Iris-setosa & 4.900 & 3 & 1.400 & 0.200 \\
Iris-setosa & 5.400 & 3.900 & 1.700 & 0.400 \\
Iris-setosa & 5 & 3.400 & 1.500 & 0.200 \\
Iris-setosa & 4.800 & 3 & 1.400 & 0.100 \\
Iris-versicolor & 5 & 2 & 3.500 & 1 \\
Iris-versicolor & 6.700 & 3.100 & 4.400 & 1.400 \\
Iris-versicolor & 5.500 & 2.400 & 3.800 & 1.200 \\
Iris-versicolor & 6.200 & 2.900 & 4.300 & 1.300 \\
Iris-versicolor & 5.500 & 2.600 & 4.400 & 1.200 \\
Iris-virginica & 6.300 & 3.300 & 6 & 2.500 \\
Iris-virginica & 5.800 & 2.700 & 5.100 & 1.900 \\
Iris-virginica & 6.500 & 3 & 5.500 & 1.800 \\
Iris-virginica & 7.400 & 2.800 & 6.100 & 1.900 \\
\hline
\end{tabular}

\subsection{Perhitungan Principal Component Analysis} (PCA)

Principal Component Analysis (PCA) dapat digunakan untuk mereduksi dimensi suatu data. PCA memberikan hasil yang baik ketika diterapkan pada atribut yang berkorelasi ( (Nasution, 2019).

Tahap pertama proses PCA adalah input data. Data disiapkan dalam bentuk matriks ukuran mxn, dimana jumlah variabel $\mathrm{n}$ akan berkurang menjadi $\mathrm{k}$ jumlah principal component yang dipertahankan. Misalkan data yang akan digunakan adalah sebagai berikut (tabel 2).

\begin{tabular}{llll}
\multicolumn{4}{c}{ Tabel 2 Sampel data input } \\
\hline $\mathbf{a 1}$ & $\mathbf{a 2}$ & $\mathbf{a 3}$ & $\mathbf{a 4}$ \\
\hline 5.100 & 3.500 & 1.400 & 0.200 \\
4.900 & 3 & 1.400 & 0.200 \\
5.400 & 3.900 & 1.700 & 0.400 \\
4.800 & 3 & 1.400 & 0.100 \\
5 & 2 & 3.500 & 1 \\
6.700 & 3.100 & 4.400 & 1.400 \\
5.500 & 2.600 & 4.400 & 1.200 \\
6.300 & 3.300 & 6 & 2.500 \\
5.800 & 2.700 & 5.100 & 1.900 \\
6.500 & 3 & 5.500 & 1.800 \\
7.400 & 2.800 & 6.100 & 1.900 \\
5 & 2.300 & 3.300 & 1 \\
5.600 & 2.800 & 4.900 & 2 \\
5.900 & 3 & 5.100 & 1.800 \\
\hline
\end{tabular}

Tahap selanjutnya adalah pre-PCA yaitu dengan melakukan standarisasi dan covariance (tabel 3), dilanjutkan dengan proses PCA. Hasilnya dapat dilihat pada gambar 6. Disini digunakan 2 principal component (pc) yang dipertahankan, yaitu pc1 dan pc2.

\begin{tabular}{lll}
\multicolumn{2}{c}{ Tabel 3} & Standarisasi dan covariance \\
\hline Component & $\begin{array}{l}\text { Standard } \\
\text { deviation }\end{array}$ & $\begin{array}{l}\text { Proportion of } \\
\text { variance }\end{array}$ \\
\hline PC1 & 2.065 & 0.925 \\
PC2 & 0.492 & 0.053 \\
PC3 & 0.280 & 0.017 \\
PC4 & 0.154 & 0.005 \\
\hline
\end{tabular}

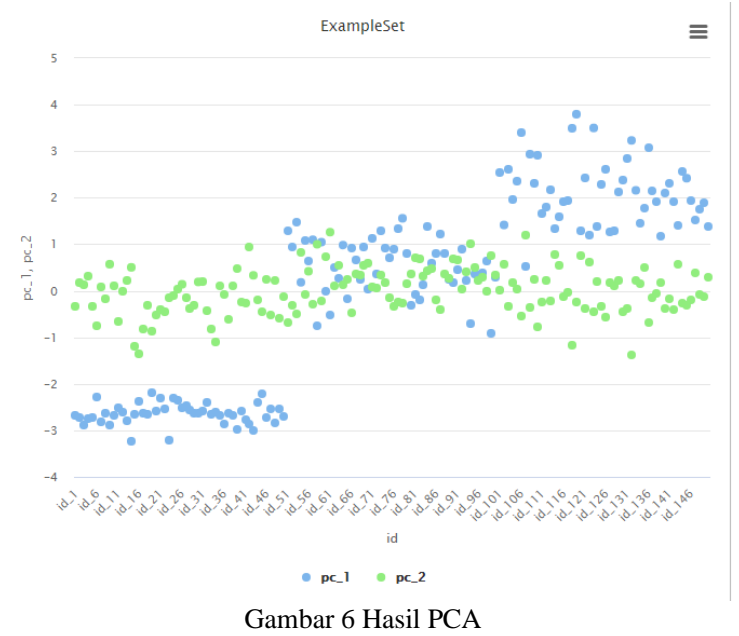

\subsection{Optimasi Decision Tree dengan PCA}

Decision tree merupakan salah satu algoritma yang populer untuk proses klasifikasi dalam mining. Mengikuti algoritma (gambar 5), proses yang dilakukan setelah mereduksi dimensi dengan PCA adalah menerapkan algoritma decision tree. Prinsip kerja algoritma decision tree adalah menggolongkan objek ke dalam kelas/label yang sudah tersedia. Termasuk ke dalam supervised learning, himpunan data bunga iris terdiri dari 3 kelas/label yaitu iris setosa, iris versicolor dan iris virginica. Dataset awal terdiri dari 4 atribut (a1, a2, a3, a4), setelah dilakukan reduksi dimensi dengan PCA hanya 2 atribut yang dipertahankan yakni PC1 dan PC2 (tabel 4).

\begin{tabular}{lll}
\multicolumn{2}{c}{ Tabel 4 Sampel data reduksi dimensi } \\
\hline Label & PC1 & PC2 \\
\hline Iris-setosa & -2.7 & 0.2 \\
Iris-setosa & -2.5 & -0.5 \\
Iris-setosa & -2.8 & 0.2 \\
Iris-setosa & -2.5 & -0.6 \\
Iris-setosa & -2.7 & -0.1 \\
Iris-versicolor & 1.3 & -0.7 \\
Iris-versicolor & 0.9 & -0.3 \\
Iris-versicolor & 1.5 & -0.5 \\
Iris-versicolor & 0.2 & 0.8 \\
Iris-versicolor & 1.1 & -0.1 \\
Iris-versicolor & 0.6 & 0.4 \\
Iris-virginica & 1.3 & 0.8 \\
Iris-virginica & 1.6 & 0.5 \\
Iris-virginica & 1.9 & -0.1 \\
Iris-virginica & 1.9 & 0.0 \\
Iris-virginica & 3.5 & -1.2 \\
Iris-virginica & 3.8 & -0.3 \\
Iris-virginica & 1.3 & 0.8 \\
Iris-virginica & 2.4 & -0.4 \\
\hline
\end{tabular}

Berdasarkan reduksi dimensi (tabel 4), langkah selanjutnya adalah pembentukan tree. Tahap awal adalah penentuan simpul melalui derajat impurity. Derajat impurity merupakan ukuran kehomogenan suatu simpul, dimana sebuah simpul dengan derajat impurity tinggi menunjukkan simpul tersebut tidak homogen, begitu sebaliknya. Pengukuran derajat impurity dataset menggunakan perhitungan gini indeks dengan formula:

$\operatorname{gini}(t)=1-\sum_{j}[p(j \mid t)]^{2}$ 
Setelah dilakukan perhitungan nilai gini indeks terhadap semua atribut, langkah selanjutnya adalah menghitung nilai gain $(\Delta)$ untuk menentukan best splitting dengan formula:

$$
\Delta=I(\text { parent })-\sum_{j=1}^{k} \frac{N(v j)}{N} \mathrm{I}(\mathrm{vj})
$$

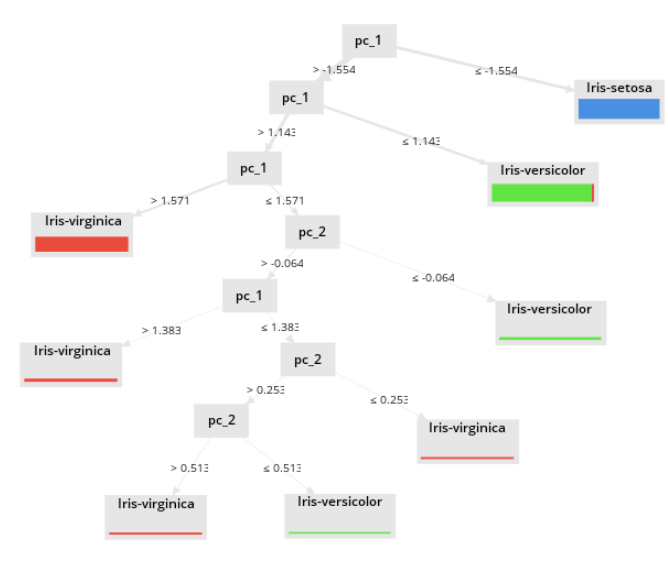

Gambar 7 Hasil klasifikasi dengan PCA dan DT

Hasil klasifikasi dengan optimasi algoritma decision tree menggunakan PCA berupa knowledge atau pola yang direpresentasikan dalam bentuk tree (gambar 7). Setelah knowledge atau pola yang ada dalam dataset berhasil diidentifikasi, selanjutnya adalah mengukur akurasi dari algoritma yang digunakan dalam proses data mining. Mengukur akurasi sebuah algoritma dalam klasifikasi dapat menggunakan rumus:

accuracy $=\frac{T P+T N}{T P+T N+F P+F N}$

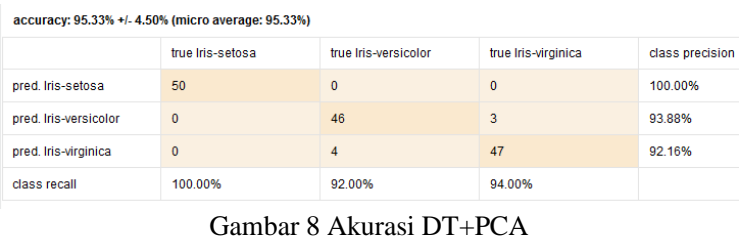

Menggunakan tools Rapidminer untuk menggali semua data, akurasi dari algoritma decision tree setelah dioptimasi dengan dengan PCA pada proses preprocessing (dimentional reduction) adalah sebesar $95.33 \%$ (gambar 8).

\section{KESIMPULAN}

Algoritma decision tree merupakan salah satu algoritma yang bersifat eager learner, dimana algoritma tersebut membaca semua data training yang digunakan untuk kemudian dikenali pola/knowledge yang tersimpan dalam data tersebut. Pola/knowledge yang sudah dikenali diterapkan pada data testing. Principal component analysis (PCA) merupakan metode yang digunakan untuk mereduksi dimensi, yang dilakukan pada tahap preprocessing. Akurasi dari algoritma decision tree setelah dilakukan optimasi dengan PCA adalah sebesar $95.33 \%$ atau meningkat $2.31 \%$ dari akurasi decision tree murni.

\section{DAFTAR PUSTAKA}

Gorunescu, F., 2011. Data Mining Concepts, Models and Techniques. Australia: Springer.

Han, J. \& Micheline, K., 2000. Data Mining: Concept and Techniques. Simon Fraser University: Morgan Kaufmann.

Maimon, O. \& Rokarch, L., 2010. Data Mining and Knowledge Discovery Handbook. 2 ed. London: Springer.

Nasution, M. Z., 2019. Penerapan Principal Component Analysis (PCA) dalam Penentuan Faktor Dominan yang Mempengaruhi Prestasi Belajar Siswa (Studi Kasus: SMK Raksana 2 Medan). Jurnal Teknologi Informasi, Volume 3, pp. 41-48.

Witten, I. H., Frank, E. \& Hall, M. A., 2011. Data Mining Practical Machine Learning Tools and Techniques. 3 ed. Burlington: Elsevier. 